\title{
Internal stem features of spring wheat varieties as factors determinig resistance to lodging
}

\author{
E.V. Ageeva ${ }^{1 *}$, I.N. Leonova ${ }^{2}$, E.A. Salina ${ }^{2}$, I.E. Likhenko ${ }^{1}$ \\ ' Siberian Research Institute for Plant Industry and Breeding - Branch of the Institute of Cytology and Genetics, SB RAS, Krasnoobsk, Novosibirsk region, Russia \\ ${ }^{2}$ Institute of Cytology and Genetics, SB RAS, Novosibirsk, Russia
}

DOI 10.18699/ICG-PlantGen2019-09

(c) Autors, 2019

* e-mail: elenakolomeec@mail.ru

\begin{abstract}
Using the anatomical method, the study of the main parameters of the internal stem structure of Russian spring bread wheat varieties was performed in order to assess their impact on resistance to lodging. An increase in the number of parenchyma vascular bundles from top to bottom was established. The decrease in the diameter of the vascular bundles is compensated for by an increase in their number. The diameter of vascular bundles in the internodes had a slight effect on resistance to lodging. The relationship between the numbers of bundles and stem diameter in both interstices was traced. Resistance to lodging correlated with the number of vascular bundles and the length of the internode EN1 and EN2. The number of vascular bundles, stem diameter and thickness of the primary cortex contribute to a high productivity of the ear. The study of anatomo-morphological traits allowed us to identify the cultivars 'Novosibirskaya 31,' 'Velut' and 'Bel', which may be of interest for breeding for resistance to lodging.

Key words: resistance to lodging; stem; vascular bundles; parenchyma; internode; wheat.
\end{abstract}

\section{Introduction}

Resistance to lodging is one of the important characteristics of modern varieties of bread wheat. Lodging results in a decline in yield and grain quality, and hampers mechanical harvesting. Resistance to lodging in plants is determined by anatomomorphological, physiological, and chemical parameters of stems (Packa et al., 2015). Anatomical characters usually include the length and diameter of the stem, the number and diameter of the vascular bundles, and the thickness of the primary cortex. However, now there is no consensus as to which parameters make the main contribution to lodging resistance. The aim of our study was to investigate the anatomo-morphological parameters of the stem in Russian varieties of bread wheat.

\section{Materials and methods}

Plant material incudes 11 Russian spring wheat varieties presented in Table 1. Plants were grown on the experimental field of Siberian Research Institute for Plant Industry and Breeding - Branch of the Institute of Cytology and Genetics SB RAS in 2018. For analysis of the stem anatomical structure, a technique developed at the All-Russian Research Institute of Grain Crops named after I.G. Kalinichenko (2009) for assessment of the conductive system of the ear's internode was used. Estimation of the internodes was carried out on the base of the method proposed by Lazarevich S.V. (1999), that is, from the internode under the ear to the internodes of the lower part of the stem. The internode under the ear was denoted 'EN1' (entre-noeud), the second from the top, 'EN2' and etc. Particular attention in the study of the internal structures of the stem of spring bread wheat in internodes EN1 and EN2 in the varieties was given to the stem diameter, the thickness of the primary cortex, the number and diameter of the vascular parenchyma bundles. Resistance to lodging was scored by a five-point standard technique. For statistical processing, an
ANOVA method were used (Dospekhov, 1985). Principal coordinate analysis of the total number of the traits was done with the use of the MRAN software Snedecor 5. The factor analysis was carried out using STATISTICA 8.

\section{Results and discussion}

The varieties 'Saratovskaya 29' and 'Novosibirskaya 18' were the most prone to lodging. Slightly sopping stems were observed in the 'Novosibirskaya 29', 'Chernyava 13' and 'Novosibirskaya 31' genotypes. The remaining samples of the set do not lodge. The number of bundles in EN1 among the studied samples varied from 14 to 24, but in EN2, from 16 to 33 (see Table 1). On average, an increase in their number from internode EN1 to internode EN2 was eight bundles. The varieties 'Bel' and 'Velut' stood out for these characters, in which 24 and 21 bundles were formed in the internode under the ear, but in the next internode, 33 and 29, respectively. The diameter of the vascular bundle in the upper internode did not exceed $260 \mu \mathrm{m}$, and in some genotypes it was below $225 \mu \mathrm{m}$. The decrease in the diameter of vascular bundles in EN1 was compensated for by the increase in their number in 'Novosibirskaya 18' (224 $\mu \mathrm{m}, 18$ bundles), 'Obskaya 2' (215 $\mu \mathrm{m}, 19$ bundles), 'Trizo' (228 $\mu \mathrm{m}, 18$ bundles) and 'Bel' (228 $\mu \mathrm{m}, 24$ bundles); in EN 2 in 'Novosibirskaya 29' (268 $\mu \mathrm{m}, 26$ bundles), 'Chernyava 13' (270 $\mu \mathrm{m}, 28$ bundles), 'Novosibirskaya 18' (262 $\mu \mathrm{m}, 28$ bundles) and 'Velut' (239 $\mu \mathrm{m}, 29$ bundles).

The varieties 'Bel' (176 and $239 \mu \mathrm{m}$ in EN1 and EN2, respectively), 'Velut' (217 and $239 \mu \mathrm{m})$ and 'Novosibirskaya 31 ' (219 and $237 \mu \mathrm{m}$ ) were distinguished by the thickness of the primary cortex. The diameter of the internode under the ear was more than $3 \mathrm{~mm}$. The largest diameter of EN1 was in 'Bel' (4.82 mm), 'Chernyava 13' (4.04 mm), and 'Novosibirskaya 31 ' $(4.07 \mathrm{~mm})$. The diameter of EN2 varied from 4.63 to $7.63 \mathrm{~mm}$, which was $2.36 \mathrm{~mm}$ larger than the aver- 
Table 1

Morphological stem indicators of spring bread wheat, 2018

\begin{tabular}{|c|c|c|c|c|c|c|c|c|}
\hline \multicolumn{5}{|c|}{ The internode under the ear (EN1) } & \multicolumn{4}{|c|}{ The second upper internode (EN2) } \\
\hline Variety & $\begin{array}{l}\text { Number of } \\
\text { bundles, pcs }\end{array}$ & $\begin{array}{l}\text { Diameter of } \\
\text { bundles, } \mu \mathrm{m}\end{array}$ & $\begin{array}{l}\text { Diameter of } \\
\text { stem, mm }\end{array}$ & $\begin{array}{l}\text { Thickness of } \\
\text { the primary } \\
\text { cortex, } \mu \mathrm{m}\end{array}$ & $\begin{array}{l}\text { Number of } \\
\text { bundles, pcs }\end{array}$ & $\begin{array}{l}\text { Diameter of } \\
\text { bundles, } \mu \mathrm{m}\end{array}$ & $\begin{array}{l}\text { Diameter of } \\
\text { stem, } \mathrm{mm}\end{array}$ & $\begin{array}{l}\text { Thickness of } \\
\text { the primary } \\
\text { cortex, } \mu \mathrm{m}\end{array}$ \\
\hline Novosibirskaya 15 & 14 & 259 & 3.22 & 164 & 25 & 275 & 5.81 & 205 \\
\hline Novosibirskaya 29 & 16 & 234 & 3.60 & 128 & 26 & 268 & 5.29 & 188 \\
\hline Bel & 24 & 228 & 4.82 & 176 & 33 & 250 & 7.63 & 239 \\
\hline Chernyava 13 & 18 & 237 & 4.04 & 160 & 28 & 270 & 6.12 & 213 \\
\hline Saratovskaya 29 & 14 & 220 & 3.18 & 147 & 16 & 254 & 4.63 & 184 \\
\hline Obskaya 2 & 19 & 215 & 3.91 & 136 & 28 & 248 & 6.42 & 164 \\
\hline Novosibirskaya 18 & 18 & 224 & 3.61 & 169 & 28 & 262 & 6.01 & 206 \\
\hline Trizo & 18 & 228 & 3.60 & 176 & 23 & 258 & 5.32 & 199 \\
\hline Novosibirskaya 31 & 23 & 245 & 4.07 & 219 & 25 & 280 & 6.42 & 237 \\
\hline Novosibirskaya 16 & 16 & 234 & 3.76 & 127 & 28 & 271 & 6.18 & 198 \\
\hline Velut & 21 & 249 & 3.81 & 217 & 29 & 265 & 6.16 & 239 \\
\hline Mean & 18 & 234 & 3.83 & 169 & 26 & 261 & 6.17 & 205 \\
\hline $\operatorname{LSD}_{0,05}{ }^{*}$ & 1.4 & 9 & 0.2 & 10 & 2.4 & 8 & 0.6 & 12 \\
\hline
\end{tabular}

* Least Significant Difference

Table 2

Results of factor analysis of anatomo-morphological features

\begin{tabular}{|c|c|c|c|}
\hline Features & $\mathrm{PC} 1 *$ & PC2 & PC3 \\
\hline $\begin{array}{l}\text { The numbers of bundles of } \\
\text { parenchyma EN1, pc. }\end{array}$ & -0.899 & 0.170 & -0.328 \\
\hline $\begin{array}{l}\text { The diameter of bundles of } \\
\text { parenchyma EN1, } \boldsymbol{\mu m}\end{array}$ & 0.308 & -0.870 & 0.336 \\
\hline The diameter stem EN1, mm & -0.862 & 0.407 & -0.076 \\
\hline $\begin{array}{l}\text { The thickness of the primary } \\
\text { cortex EN } 1, \boldsymbol{\mu m}\end{array}$ & 0.619 & -0.504 & -0.467 \\
\hline $\begin{array}{l}\text { The numbers bundles of paren- } \\
\text { chyma EN2, pc. }\end{array}$ & -0.801 & 0.264 & 0.347 \\
\hline $\begin{array}{l}\text { The diameter bundles of paren- } \\
\text { chyma EN2, } \mu \mathrm{m}\end{array}$ & 0.081 & -0.864 & 0.194 \\
\hline The diameter stem EN2, mm & -0.901 & 0.289 & 0.145 \\
\hline $\begin{array}{l}\text { The thickness of the primary } \\
\text { cortex EN2, } \mu \mathrm{m}\end{array}$ & 0.804 & -0.451 & -0.268 \\
\hline Resistance to lodging & 0.469 & 0.080 & 0.718 \\
\hline
\end{tabular}

* PC, principal component

age diameter of the upper internode among the samples. The variety 'Bel' was characterized by the thickest stem from the whole set, the diameter of EN2 was $7.63 \mathrm{~mm}$. The thinnest stem was in 'Saratovskaya 29', $4.63 \mathrm{~mm}$.

In terms of all the features studied, the varieties 'Velut' (71.0), 'Novosibirskaya 31' (67.3) and 'Bel' (67.0) had the largest number of weighted ranks. The correlation analysis reflected the presence of significant correlations between the length of the stem and the length of the upper internode $(\mathrm{r}=0.91)$. A positive correlation of the average degree $(\mathrm{r}=0.59-0.37)$ was noted between the number of vascular parenchyma bundles and resistance to lodging. The correlation between the stem diameter in EN1, EN2 and resistance to lodging did not exceed 0.21 .
Estimation of the obtained data by the principal component analysis established that the first three components account for $93.65 \%$ of the total variance. Of these, $52.26 \%$ is explained by the first component, $28.87 \%$, by the second, and $11.52 \%$, by the third. The first component is related to the main parameters of the stem in the internodes studied: the number of vascular bundles of the parenchyma, the diameter of the internode and the thickness of the primary cortex (Table 2).

The relationship between the number of bundles and stem diameter in both internodes was established. At the same time, a decrease in the indices of these features results in an increase in the thickness of the primary cortex.

The leading role in the first component belonged to the stem diameter in EN2 $(-0.901)$ and the number of vascular 
parenchyma bundles in EN1 (-0.899). A number of authors claim that stem diameter and number of vascular bundles are related to the productivity of the ear (Skripka, 2012; Zakharov et al., 2014).

The second component is related to the diameter of the vascular bundles of the parenchyma in the internodes studied. The analysis of this factor showed that it has a significant negative correlation with the diameter of the vascular bundles in EN1 and EN2. It can be assumed that the selection of plants with a smaller diameter of the bundles of the parenchyma layer may be effective.

The greatest load of the third component is observed in resistance to lodging, in the thickness of the primary cortex in the upper internodes and in the number of vascular bundles in EN2, a significant positive relationship was noted only with resistance to lodging $(0.718)$. The feature of resistance to lodging is positively correlated with the number of bundles of parenchyma in EN2 and with the diameter of the bundles in EN1, while an increase in the thickness of the primary cortex and the number of bundles in the upper internode have a negative effect on the resistance to lodging.

Anatomo-morphological features have been identified, which correlate with wheat resistance to lodging (number of vascular bundles, length of internodes EN1 and EN2) and can cause the implementation of high ear productivity (number of vascular bundles, stem diameter and thickness of the primary cortex). It was found that the varieties 'Novosibirskaya 31', 'Velut' and 'Bel' are characterized by the most optimal com- bination of parameters such as stem diameter, number of vascular bundles and resistance to lodging which allows us to recommend them for breeding.

\section{References}

Packa D., Wiwart M, Suchowiska E., Bienkowska T. Morpho-anatomical traits of two lowest internodes related to lodging resistance in selected genotypes of Triticum. Int. Agrophys. 2015;29:475-483. DOI 10.1515/intag-2015-0053.

Ionova E.V. The method to assess the level of development of the conductive system of the ear's internode of winter wheat with different water availability. Grain Economy Russia. 2009;4:18-22 (in Russian).

Lazarevich S.V. The evolution of the anatomical structure of the stem of wheat. Minsk: Bel. ed. partnership "Hut", 1999. 295.

Dospehov B.A. The technique of field experience. Moscow: Agropromizdat, 1985;244-268.

Skripka L.F. Features of the anatomical structure of the stem of winter wheat against the background of making complex compost. Ecological Bulletin of the North Caucasus. 2012;3:79-87.

Zakharov V.G., Syukov V.V., Yakovleva O.D. Conjugation of anatomo-morphological features with resistance to lodging of spring soft wheat in the conditions of the Middle Volga region. Vavilov J. Genet. Breed. 2014;18(3):506-510 (in Russian).

Acknowledgments. Russian Science Foundation (project 16-16$00011-P$ ) supported this work. Plant cultivation was carried out in the framework of the IC\&G budget project No. 0324-2019-0039.

Conflict of interest. The authors declare no conflict of interest. 